\title{
Aportes desde las Prácticas del Fracaso al campo emergente de los estudios artísticos
}

\section{Artículo de reflexión}

\section{Juan Fernando Cáceres Jaramillo}

Universidad Distrital Francisco José de Caldas

cjjuanf@correo.udistrital.edu.co

Recibido el: 10/09/2020

Aceptado el: 15/02/2021

Cómo citar este artículo: Cáceres Jaramillo, J. F. (2021). Aportes desde las Prácticas del Fracaso al campo emergente de los estudios artísticos. Calle 14: revista de investigación en el campo del arte. 16(30), pp.360373. https://doi.org/10.14483/21450706.18306 


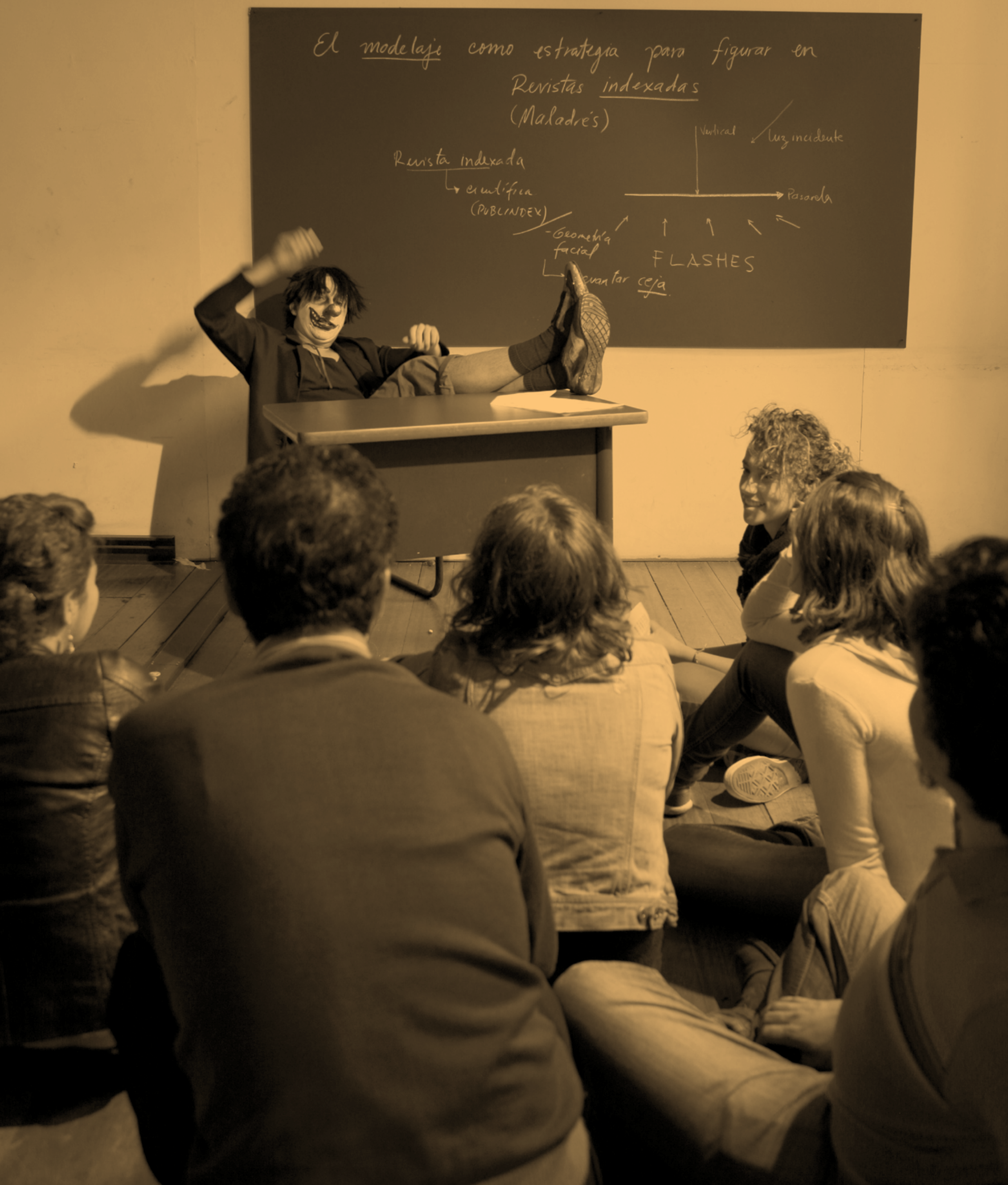


Aportes desde las Prácticas del Fracaso al campo emergente de los estudios artísticos

\begin{abstract}
Resumen
Los estudios artísticos se definen como un campo donde se piensa de manera crítica la modernidad, desde una perspectiva decolonial. Situados en "la frontera", desde la Maestría y el Doctorado en Estudios Artísticos de la Universidad Distrital se empiezan a configurar las bases epistémicas y metodológicas que servirán de hoja de ruta para el desarrollo de las investigaciones/creaciones que se afincan ya en sus espacios académicos. Se pretende hacer un aporte a este ejercicio de construcción a partir de las agitaciones teóricas y artísticas que se han suscitado alrededor del ejercicio indisciplinante en Prácticas del Fracaso, un proyecto que surgió bajo la batuta del afamado clown Maladrés y que ahora es objeto de estudio dentro del doctorado. Para ello se cruza el concepto de frontera con el de paréntesis y se enuncian aspectos transversales que comprometen la creación artística, la concepción de la obra de arte y la performatividad.
\end{abstract}

Palabras claves

Estudios Artísticos; fracaso; indisciplinamiento; investigación/creación; paréntesis

\begin{abstract}
Artistic Studies are defined as a field where modernity is examined critically, from a decolonial perspective. Located at "the border", from the Master's Degree and the Doctorate in Artistic Studies of Distrital University, the epistemic and methodological bases, that are beginning to be configures, will serve as a roadmap. The intention is to make a contribution to this construction exercise based on the theoretical and artistic agitations that have arisen around the indisciplinary exercise in Prácticas del Fracaso, a project that arose under the leadership of the famous clown Maladrés, and which is now studied in the doctorate. For this, the concept of border is intercrossed with that of parentheses and they are enunciated transversal aspects that compromise the artistic creation, the conception of the work of art and performativity.
\end{abstract}

\title{
Keywords
}

Art Studies; failure; indiscipline; research / creation; parenthesis

\author{
Résumé \\ Les études artistiques sont définies comme un domaine où la modernité est examinée de \\ manière critique, dans une perspective décoloniale. Situées à « la frontière ». Depuis le Master \\ et le Doctorat en Études Artistiques, on commence à configurer les bases épistémiques et \\ méthodologiques qui serviront de feuille de route pour le developpement des recherches/ \\ créations déjà établies dans leur espaces académiques. Nous entendons apporter une \\ contribution à cet exercice de construction basé sur les agitations théoriques et artistiques qui \\ ont surgi autour de l'exercice indisciplinaire dans Prácticas del Fracaso, un projet qui est né \\ sous la direction du célèbre clown Maladrés, et qui fait maintenant un objet d'étude au doctorat. \\ Pour cela, la notion de frontière est entrecroisée avec celle de parenthèses et des aspects \\ transversaux sont énoncés en compromettant la création artistique, la conception de l'œuvre \\ d'art et la performativité.
}

\section{Mots clés}

Études artistiques ; échec ; indisciplinaire ; recherche / création ; parenthèse 
Contribuições a partir das Práticas do Fracasso ao campo emergente dos Estudos Artísticos

\section{Resumo}

Os Estudos Artísticos se definem como um campo onde se pensa de maneira crítica a modernidade a partir de uma perspectiva decolonial. Situadas <<na fronteira $>$, se começam a configurar, a partir do Mestrado e do Doutorado em Estudos Artísticos da Universidade Distrital, as bases epistêmicas e metodológicas que servirão de roteiro para o desenvolvimento das investigações/criações que se estabelecem em seus espaços acadêmicos. Se pretende fazer uma contribuição a este exercício de construção a partir das agitações teóricas e artísticas que surgiram ao redor do exercício indisciplinar em Práticas do Fracasso, um projeto que surgiu sobre a batuta do Famoso Clown Maladrés e que agora, é objeto de estudo dentro do doutorado. Para isso, se cruza o conceito de fronteira com o parêntesis e se enunciam aspectos transversais que comprometem a criação artística, a concepção de obra de arte e a performatividades.

\section{Palavras chave}

Estudos Artísticos; fracasso; indisciplinar; investigação/criação; parênteses

\section{Tandarisunchi maki kawanakungapa mana llapa suma riura ruraikuna iachakunakura}

\section{Maillallachiska}

Iachaikunaku Ilpa suma pangapi rurangapa Nukanchipa kunauramanda kausaita, sugkuna kankuna ajai iachagkuna, iachaikuskakuna Universidad Distrital sutipi kai sug rura chasallata iacha suti Afamado Clown Maladrés, munaku kanchasinama kawachinga, suura sug kunawa llakichi wanta chasapas chara katichi.

\section{Rimangapa Ministidukuna}

Iachaikui pangapi ruraikuna apachingapa; manima allilla riska llakii; manima ulladur; Ilapatapuchii tatichidur; ruradur mailla sulladur 


\section{Introducción}

Uno de los retos más importantes del Doctorado en Estudios Artísticos de la Universidad Distrital Francisco José de Caldas es definir las perspectivas epistemológicas y las apuestas metodológicas que le competen al campo de los estudios artísticos como tal. Para empezar, se plantea que una de las finalidades de este campo sería la apertura de las fronteras disciplinares e intradisciplinares, generando un diálogo de conocimientos, saberes, prácticas y oficios, en pro de la construcción relacional de comunidades de pensamiento colaborativo, que concentren una especial atención en la constante emergencia de otros modos de ser, estar, indagar, crear y vivir en el mundo. Los estudios artísticos serían, entonces, un espacio inter, trans e indisciplinar cuya plataforma fundante es el campo de las artes, y estarían configurados desde la crítica, la práctica, la intervención y la lucha.

No obstante, es importante decir que no es un espacio neutro, ya que, por un lado, es punto de encuentro de las experiencias de vida de los diferentes actores participantes (doctorandos, docentes, invitados, administrativos), los cuales aportan desde sus miradas condicionadas y condicionantes; por otro lado, se configura como una apuesta académica que ejerce resistencia, intervención e insurgencia contra los discursos hegemónicos neoliberales, dominantes y reoccidentalizantes. Por ello, se apunta hacia una creación colectiva de conocimiento que se desmarque de las concepciones universalizantes propias del cientificismo dogmático que impera en las academias, dando trámite a vectores que perforen la estética y las epistemes instauradas.

Entre los discursos hegemónicos, las disciplinas perpetúan la colonialidad modernista del conocimiento, reduciendo la realidad a un espacio limitado. Dicho espacio solo permite una única mirada, la que se para sobre las representaciones de la certeza academicista de la ciencia y deja a un lado la posibilidad de una construcción de mundos posibles desde la fantasía creadora y el conocimiento imaginado. Como respuesta a esto, la interdisciplinariedad y la transdisciplinariedad, por su parte, conllevan per se una intención indisciplinar. Dicho indisciplinamiento comprende una transformación política y ética, pero también y sobre todo, en palabras de Pedro Pablo Gómez (2018), epistémica y estética ${ }^{1}$.

1 A estas cuatro dimensiones, habría que sumar la erótica, en tanto pulsión vital y posibilitadora del deseo.

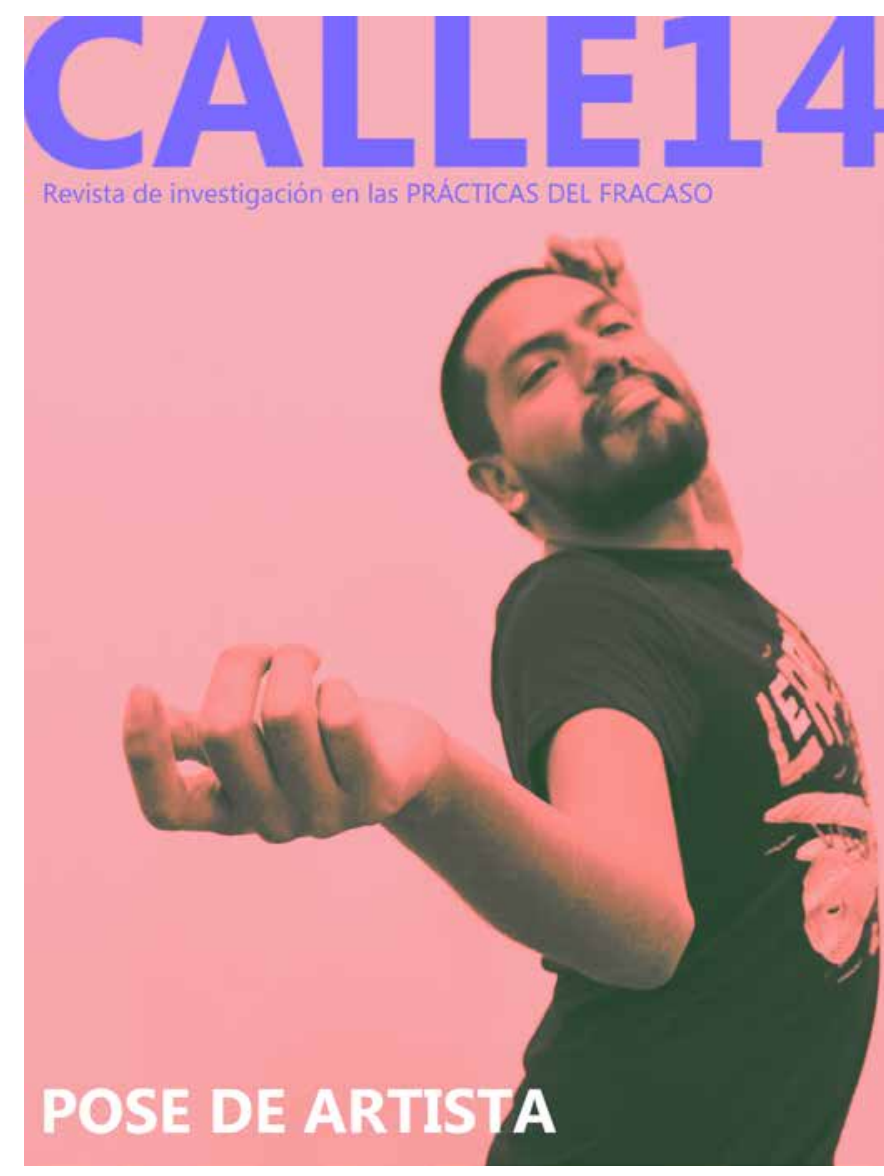

Imagen 1. Maladrés. Portada de Calle 14, Revista de investigación en las Prácticas del Fracaso. UDFJC. 2019.

El término indisiciplinamiento ha sido abordado por varios autores, haciendo referencia a una apertura de las disciplinas. El indisciplinamiento, que aboga por el insistente cuestionamiento de la disciplina a partir de la disciplina misma, tiene un trasfondo aún más ambicioso. Atendiendo a lo que dice Gabriel Kaplún en Indisciplinar la Universidad (2005), «las disciplinas son prisiones. Abrirlas, creemos, resulta imprescindible para poder cuestionar un disciplinamiento mayor: el de la globalización neoliberal». Kaplún propone, para este «esfuerzo indisciplinador», hacer una revisión de tres aspectos propios de la universidad: la producción de conocimientos, los procesos de enseñanza y aprendizaje y el vínculo con la sociedad. En esta dirección, se hace necesario el uso de herramientas creativas y pedagógicas diferentes que provoquen un rompimiento contra académico, tanto en el mundo del arte como en la academia misma.

En ese sentido, el reto de indisciplinar las disciplinas está ligado a la práctica artística y pedagógica, en cuanto implica un rebelar(se) y un revelar(se), cuestionando los límites propios de la dimensión disciplinar. 


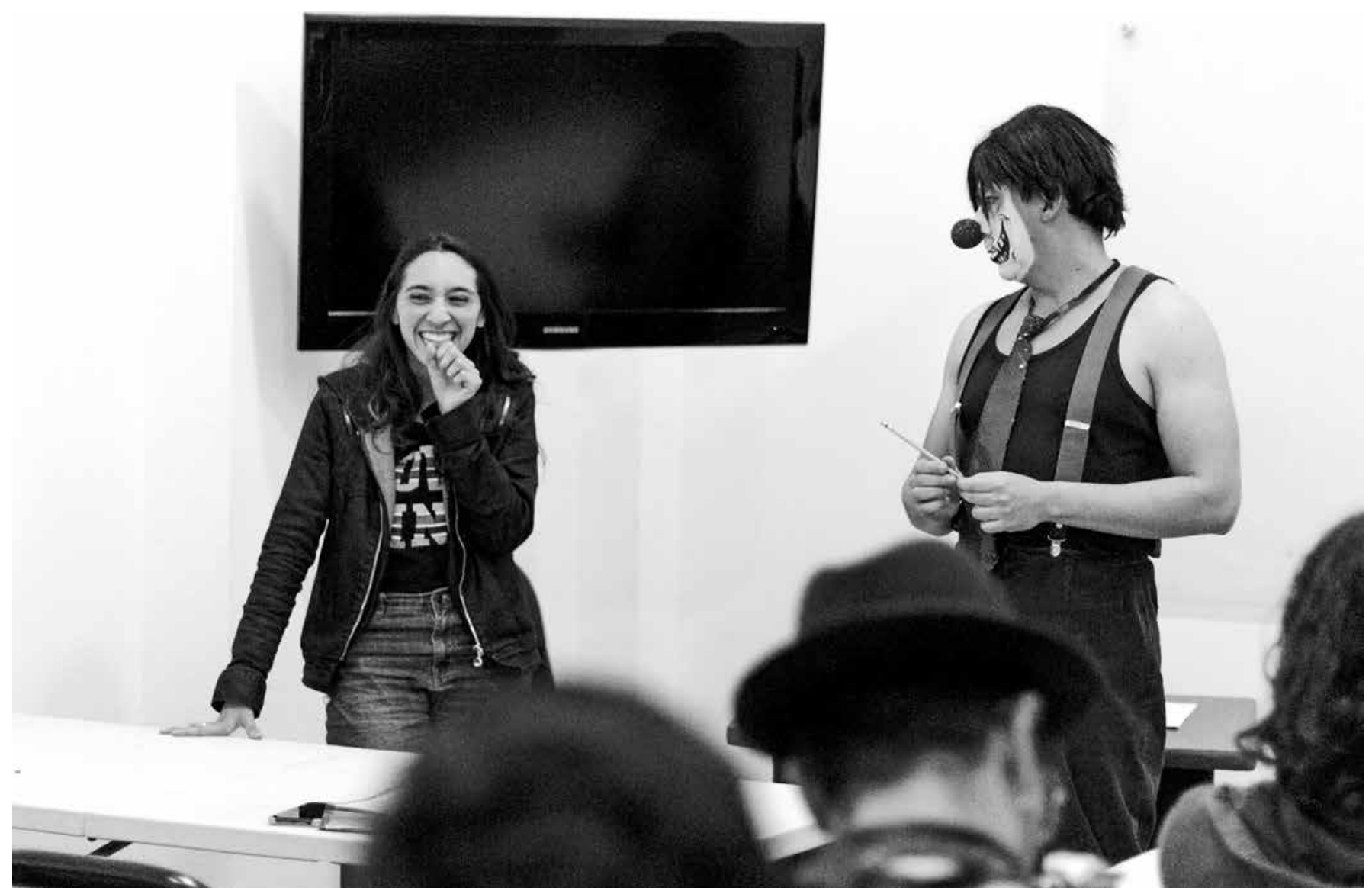

Imagen 2. La Monitora Estrella. Prácticas del Fracaso. UDFJC. 2019.

En lugar de abandonar la disciplina, se trata de abrirla y dejar que permee, elaborando, a la manera como lo propone Alex Schlenker (s.f.), estrategias contracognitivas que traten de desestabilizar, a través del diálogo y la apropiación, esos lugares tradicionales del conocimiento universal. Son necesarias, entonces, otras maneras de pensar y actuar que ayuden a desmantelar esa imagen que tenemos del mundo, que no es más que un coercitivo constructo moderno. ¿Cuál es, entonces, nuestra apuesta contrahegemónica, aquella que brote de nuestros contextos particulares y que atienda a nuestras propias contingencias? Es, a mi parecer, la constitución de una ruta que abogue por la iconoclastia, atacando nuestras representaciones del conocimiento a través de un camino que suponga un ejercicio continuo de vaciamiento ${ }^{2}$.

2 El sentido con el que se aborda el término 〈vaciamiento en este texto, es el de la <contrarrepresentacionalidad), es decir, del despojarse de las representaciones que coartan nuestro pensamiento, en una búsqueda (utópica, por qué no) de las representaciones primarias que surgen de la experiencia misma y que no han sido tramitadas por la cultura.
Para ello, es necesario dirigirse hacia la frontera, ubicarse en el margen. Dicha frontera no es necesariamente el borde que colinda con lo externo (inter, trans), también es el lugar por donde se abre la grieta interna (del sistema), esa que nos llama a arrojarnos a un abismo interior. El campo de lucha, traducción, negociación y articulación del que habla Gómez (2018) incluye el reto de la creación de cartografías que configuren nuestro propio entendimiento y de la identificación de ese topos inexplorado que llamamos vacío.

\section{La investigación/creación en los estudios artísticos}

Una de los retos del campo de los estudios artísticos es el posicionamiento del debate acerca de la investigación/creación. Esta categoría relacional-diferencial no jerarquizadora (Gómez, 2016) debe problematizarse constantemente. En la investigación/creación se considera a la obra de arte y a la práctica artística como una manifestación de pensamiento y conocimientos sensibles, lo que permite que la creación artística se enriquezca con preguntas de la investigación, con 
otros campos de relación posibles y con conocimientos plurales, heterogéneos y no totalizadores, con el fin de superar incluso la interdisciplinariedad y lograr una transdisciplinariedad o, en el mejor de los casos, una indisciplinariedad.

Esta convicción trans e indisciplinaria tiene como objetivo repensar la creación artística más allá de la estética y del campo del arte moderno, a través del reconocimiento de la creación aesthésica, la cual fue dejada de lado por estética moderna. ¿Cómo se pueden construir los puentes que comuniquen la investigación con la creación, que borren el distanciamiento entre el sujeto y el objeto generado por la ciencia y la estética y que reconstituyan el sentido de la aiesthesis?

Ya una vez, en el texto Práticas do Fracasso II, recurrí al despliegue de lo que allí denomino «nuevas miradas producto de ciertas asociaciones irracionales», con el fin de concretar algunas apuestas que me son propias y que pueden servir de insumo a lo que se entiende como <investigación-creación〉. Estas apuestas son: (i) La concepción de una academia flexible que debe olvidar su lado solemne y que debe relativizarse a través de la ruptura, la disonancia y la libertad; (ii) la noción de la economía a través del desprecio del objeto artístico, pues si el arte pertenece hoy en día al dominio de la realidad, ésta última lo desborda por todas partes; (iii) el investimiento de la realidad, explorando territorios más vastos que los del arte mismo y donde lo que importa no es la trascendencia sino la existencia; (iv) el uso de gestos primarios que permitan la reconstrucción de una narrativa de la vida y un retorno a la (re) presentación prosaica y elemental, porque todo es digno de atención; ( $v$ ) la democratización de las ideas representadas, para que el saber pueda fluir y hacer así del arte un lenguaje a la vez integrado, capaz de ser escuchado, pero siempre en disonancia; (vi) la noción de que el artista es un hacedor y él se sostiene sobre la acción y es a través de la acción que puede intervenir socialmente; (vii) el retorno a una «mirada originaria», que se proyecta hacia un futuro sin condiciones, desde la que se ve el mundo como si fuera la primera vez y desde donde no se prejuzga lo que sucede a nuestro alrededor; (viii) la búsqueda, a través de la abstracción (porque todos los lenguajes son abstractos), de ese espacio mental donde las ideas empiezan a tomar forma y, en ese sentido, la búsqueda a través de la complejidad y la pluridireccionalidad, pues el desplazamiento de la actividad artística hacia la abstracción compromete las prácticas de la intersubjetividad, la compartición y, por qué no, la creación colectiva, en pro de los que Gómez (2018) reclama: conocimientos plurales, heterogéneos y no jerarquizados; (ix) la potencia de

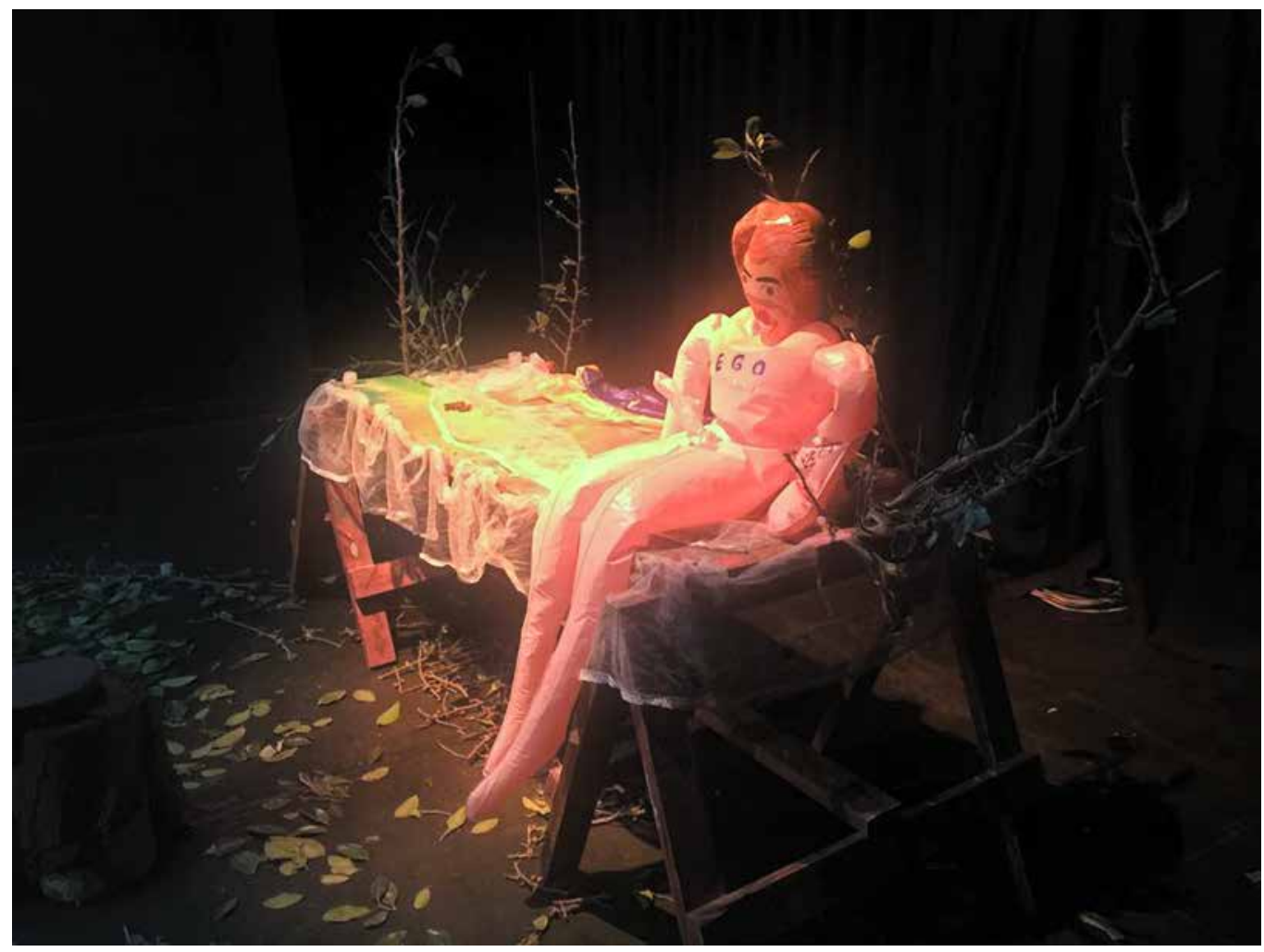

Imagen 3. Algún estudiante de PDF. Ego Augusto en el escenario. 2017. 


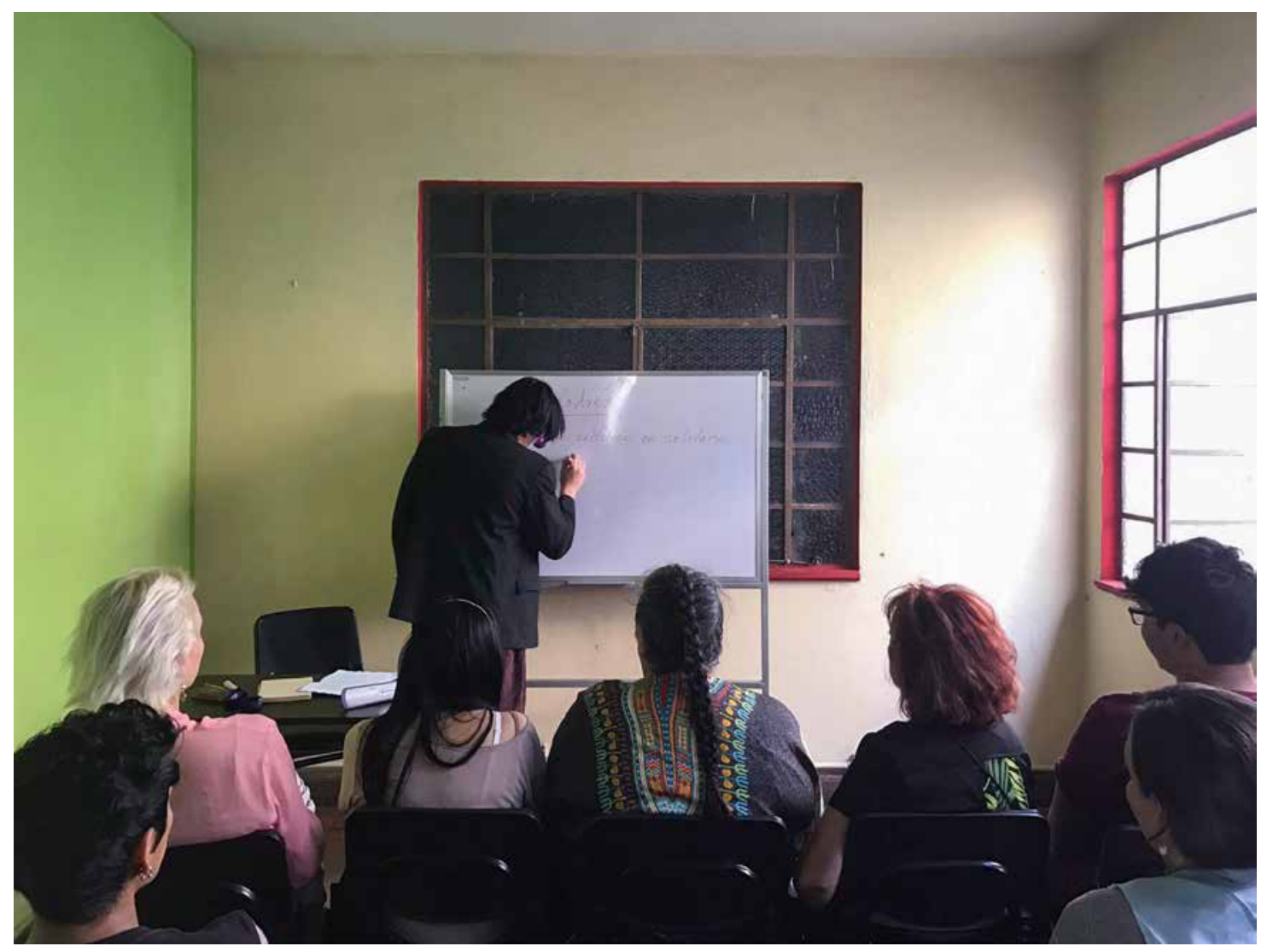

Imagen 4. Euler, L. Maladrés en Guatemala. Festival Internacional de Performance Forma y Sustancia. 2017.

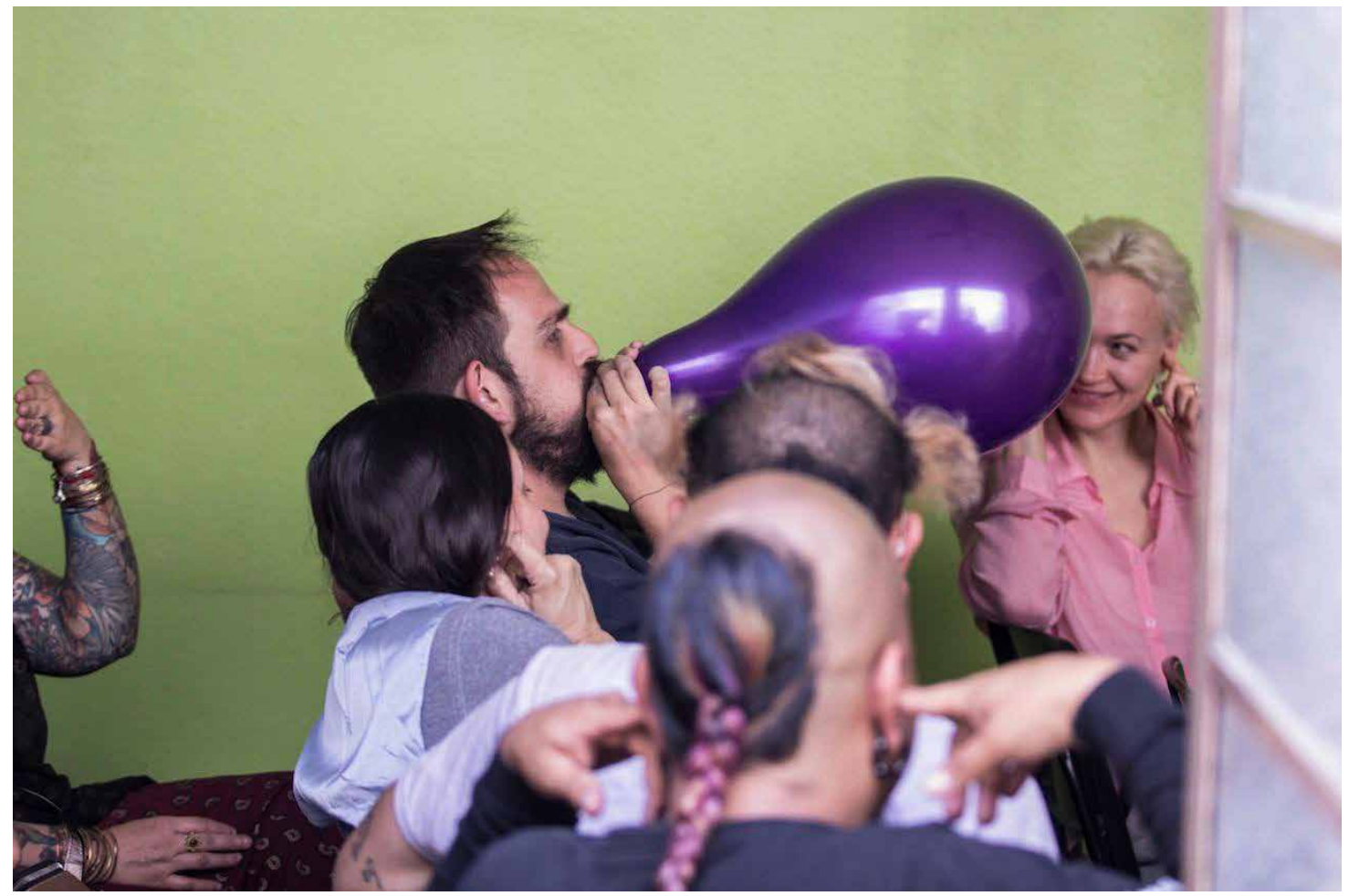

Imagen 5. Euler, L. Pancho inflando un globo hasta antes de que se reviente. Festival Internacional de Performance Forma y Sustancia. 2017. 


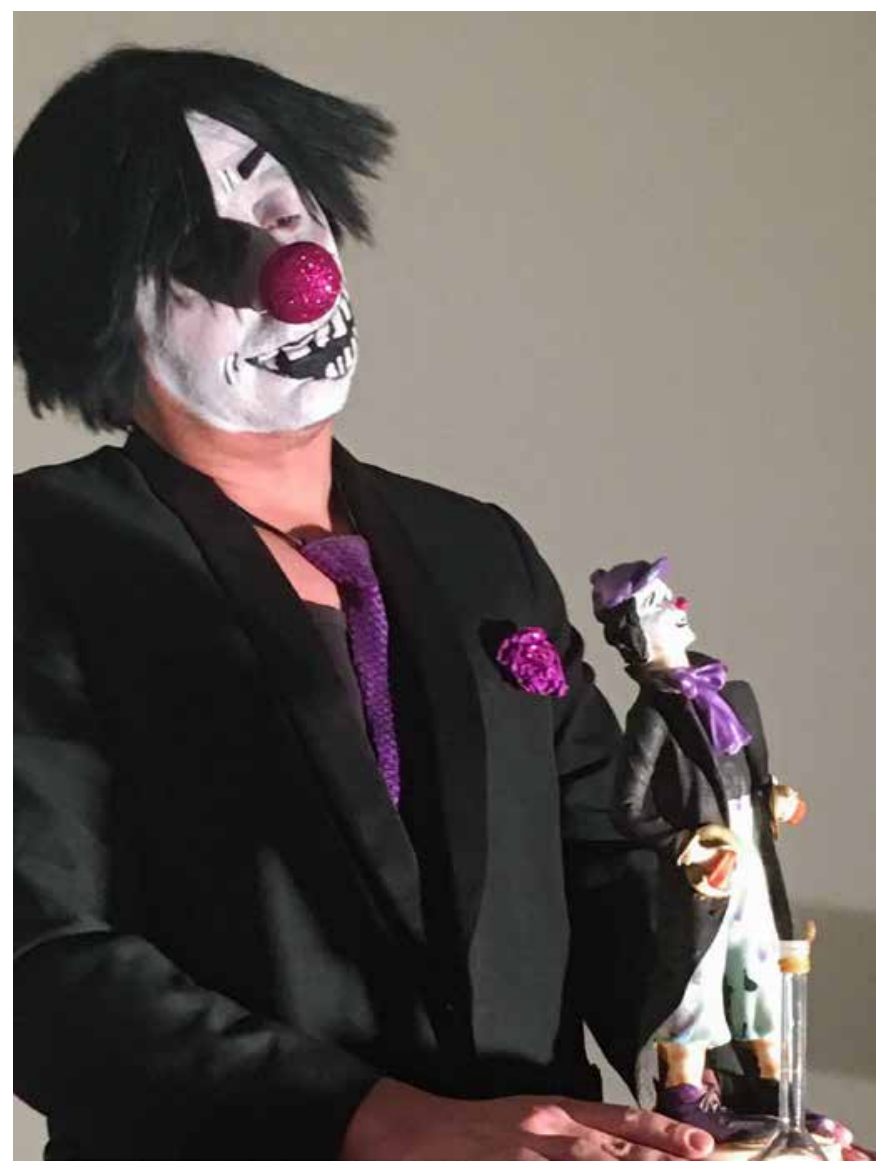

Imagen 6. Nieto, J. El payaso, ¿un asunto académico? UDFJC. 2017.

un cuerpo originario que se presenta al mundo como un instrumento de conocimiento y que sobrepasa al artista mismo, su humanidad y su animalidad (Cáceres, 2015).

Estas apuestas constituyen también un aporte a la manera como se abordan las prácticas y las metodologías en el campo de los estudios artísticos, donde se convoca el pensar, el sentir y el hacer, en una dirección que no apunta al centro, sino que de manera crítica se sitúa en el borde, poniendo en evidencia la colonialidad del saber. Para ello es fundamental la forma como se esté abordando el arte, pues desde este campo, el de los estudios artísticos, se superan ya las nociones de representación y repertorio, para desbordarse hacia la vida en sí (del ser humano y de las comunidades que integra). Así como el mundo sensible ha sido colonizado por la estética moderna, los estudios artísticos, parados en las nociones de investigación/creación y de indisciplinamiento, convocan de nuevo a la aiesthesis, desclasificándola, poniendo a su servicio la poética y la prosaica y fundando, a partir de ella, otros mundos posibles.

Ahora bien, a la «frontera» planteada por los estudios de perspectiva decolonial, lugar que habitamos y desde donde es posible adoptar el pluralismo de alternativas y modos de ser y evidenciar esa «herida» que nos escuece, sumo también la idea de otro borde, el del «paréntesis», el lugar de la grieta y del silencio, lugar desde el cual también podemos actuar.

\section{El paréntesis (y el fracaso)}

Urge concentrarse en el paréntesis, en el espacio en blanco, aquél lugar donde se dibujan los vacíos. Urge poner atención al silencio, aquél que hace posible el lenguaje articulado, el que hace viable que la música tenga efecto. Ítalo Calvino (2012), en el capítulo «El silbido del mirlo» de su libro Palomar convoca el sentido del silencio (de la pausa entre silbido y silbido) como el lugar donde reposa el significado del lenguaje: «¿Si los mirlos se hablaran en el silencio? (El silbido sería en este caso solo un signo de puntuación, una fórmula como <Terminado. Cierro〉). Un silencio en apariencia igual a otro silencio, podría expresar cien intenciones diversas; también un silbido, por lo demás; hablarse callando o silbando, es siempre posible: el problema es entenderse».

El afamado clown Maladrés (2016), por su parte, en su texto Discurso Inaugural nos recomienda poner atención a las pausas: «Debo dejar una pausa cuando quiera que algo de lo que vaya a decir se profundice. Se supone que ustedes deben notarlo inmediatamente mirando, enderezándose, inclinando su cabeza hacia un lado y realmente escuchando el silencio. (...) Pausas con naturalidad, no para ponerme lento o mostrar debilidad, sino pausas para demostrar que domino esto tan bien, que estoy hablando como un experto». Y es que es en ese silencio donde reposa lo inexplorado. La atención concentrada en el contenido evidente del conocimiento (lo ya dicho, lo racionalmente verificado) se rehúsa a hurgar en el intersticio que posibilita la cohesión de las estructuras, a saber: el paneo de las esquinas muertas entre escena y escena de las películas de cine donde reposa el fantasma y el gazapo, el conector entre párrafo y párrafo que conduce o que niega lo anteriormente afirmado, la eterna espera en la escala en un aeropuerto en medio del he partido y el ya quiero llegar, la mirada coqueta que duda antes de un primer <te quiero>, el aliento robado entre beso y beso, los puntos suspensivos que me indican que el autor deliberadamente ha excluido alguna parte del texto que no quiere que se lea, el lienzo crudo que sobresale como un color más en la pintura postimpresionista de algún pintor holandés de renombre, el pie de página anecdótico-aclaratorio que abre puntos de fuga en la 


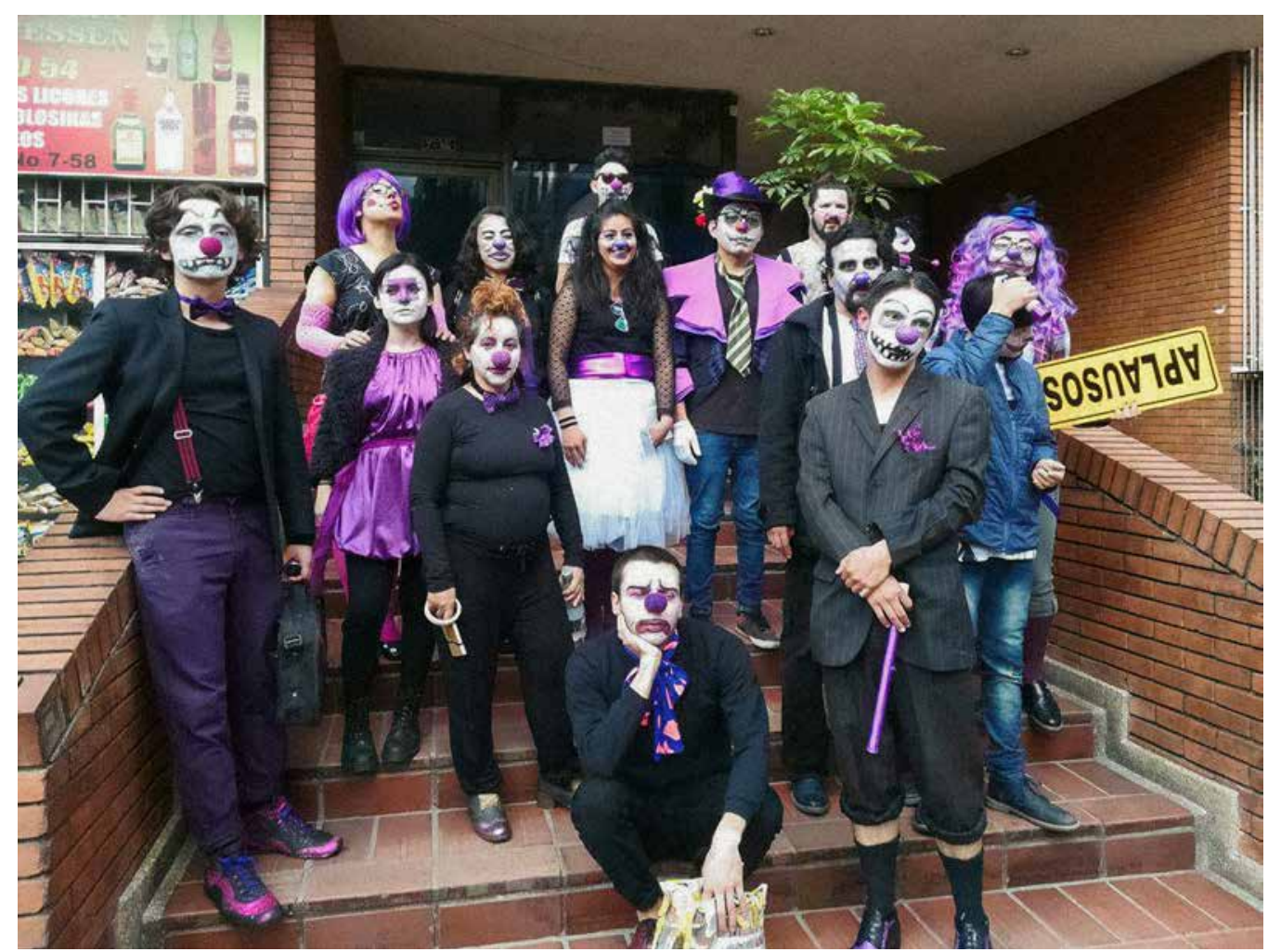

Imagen 7. Algún estudiante de PDF. El fracaso final. Bogotá. 2018.

argumentación... La pausa, el reposo, el valle, la caída el abismo, lo oscuro, la grieta, la huida, el borrón, el tachón, la fuga y, por ende, el borde, el vacío y, claro está, el fracaso.

Para hablar de fracaso es inevitable acudir a Samuel Beckett. Es este autor quien, en su texto Worstward Ho propone la célebre frase «Da igual. Prueba otra vez. Fracasa otra vez. Fracasa mejor» (Beckett, 1983). El reto de abandonarse a las condiciones que nos impone el fracaso, en un mundo en el que lo único que debe naturalizarse ${ }^{3}$ es el éxito, es desde ya una manera de desmarcarse y abrir campos de lucha, basados en la heterogeneidad, la discontinuidad, la incoherencia y el conflicto. La aceptación del fracaso ontológico como

3 «¿Es la modernidad un proyecto fundamentalmente estético que funda diversas formas de colonialidad? Esto se sustenta en la medida en que la modernidad se ha entendido como un proyecto de construcción de la <imagen del mundo» (Gómez, 2018, 75). Las naturalizaciones ratifican la construcción de una imagen artificial del mundo que podría incluso ocupar su lugar. Es necesario identificar esos elementos que han sido instalados en el pensamiento y que, en algún momento de la vida, se han considerado como una verdad absoluta, y determinar, a su vez, las implicaciones que conllevan. Podríamos enunciar algunos ejemplos que vienen al caso del presente artículo: el artista-docente es un artista fracasado; la academia es el lugar del conocimiento; Europa es la cima civilizatoria; el verdadero arte no es decorativo ni artesanal, etc. «parte del camino» que plantea Garzón (2019), citando a Grossberg, es tal vez la primera «práctica del fracaso». En mi caso, la del hombre que no es del todo <hombres, la del artista que no es del todo <artista〉, la del profesor que no es del todo <profesor $y$, en definitiva, la del payaso que no es del todo 〈payaso>. Y creo que es mejor así, pues «podemos preferir, como lo preferiría Palomar, <la persecución continua de una precisión insegura en el definir lo modulado, lo cambiante, lo compuesto, esto es, lo indefinible» (Calvino, 2012)4. Se hace un llamado, entonces, a desobedecer la colonialidad en el hacer, en el pensar y en la regulación del deseo y el gusto y repensar, así, las diferentes maneras como hemos naturalizado múltiples aspectos del vivir que nos han sido impuestos desde una estructura que, al parecer, nos supera pero que, no por eso, debemos dejar de combatir. La resistencia, cuyo lugar de activación principal emerge en nuestra corporeidad, es una fuerza

\footnotetext{
$4 \quad$ Ante la pregunta 〈genealogista del quiénes somos y cómo llegamos a ser lo que somos (traída a colación por María Teresa Garzón en Contragenealogías del silencio: una propuesta desde los estudios culturales feministas (2019), se superponen otras preguntas tal vez más potentes: ¿Qué de lo que está oscuro (no develado) me define? ¿Dónde puedo encontrarlo? ¿Cuáles son los aspectos que me construyen como sujeto (poroso) y que he tachado? ¿Qué gritan los silencios que configuran mi realidad? Ante un claro afán de categorización, ¿cómo asir lo inasible y definir lo indefinible?
} 


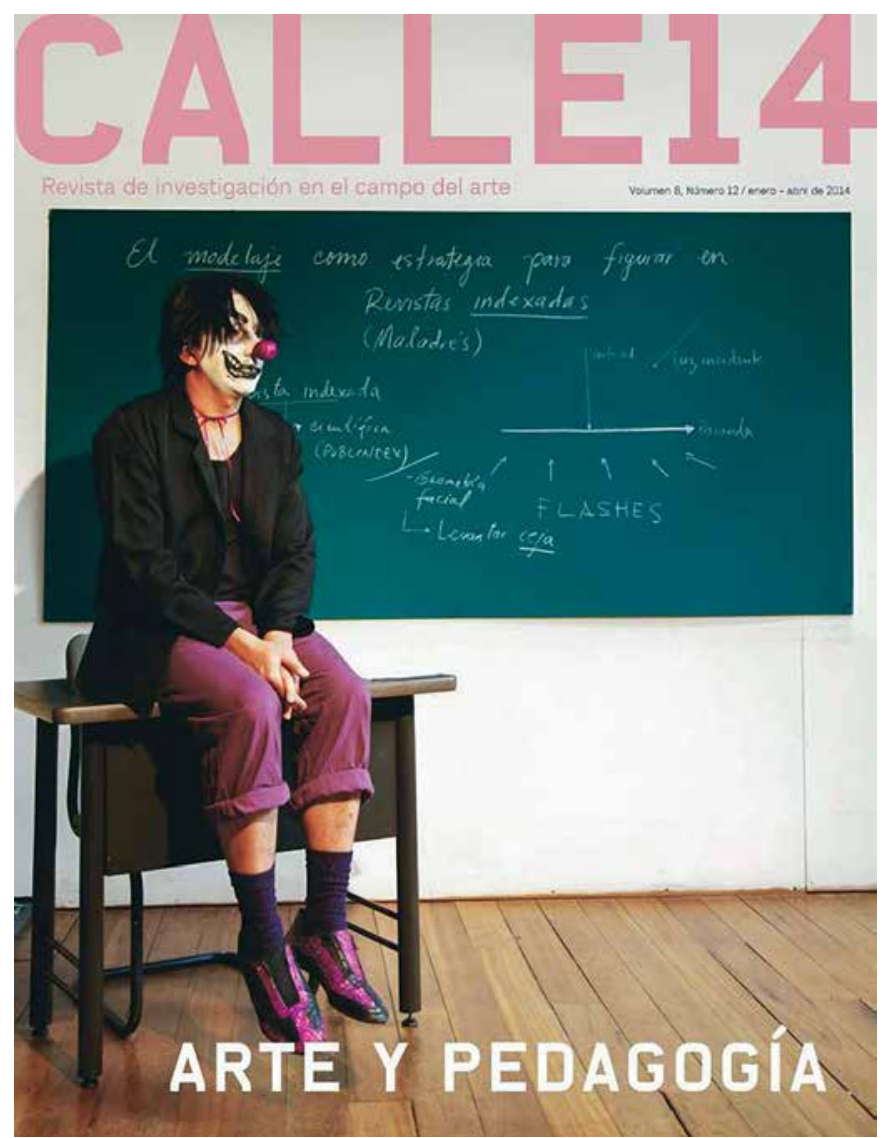

Imagen 8. Ayala, A. Portada de la Revista Calle 14. UDFJC. 2015.

representada por un sistema de vectores mutables que apuntan hacia el desmonte de «algunos inamovibles que nos han sido otorgados» (Quijano, 2000).

Dentro de ese ejercicio de resistencia, la poética cumple un papel fundamental, debido a que la imaginación y la fantasía, muchas veces mutiladas en el acto atroz de administrar el conocimiento, abren el umbral a otros mundos y otras realidades, llenos de relaciones inéditas. Allí también es necesario, en medio de esta decadencia disciplinaria, dar paso a estas otras formas de conocimiento, que surgen de modo transitorio y bajo condiciones concretas, impulsadas por sujetos colectivos y por comunidades temporales. Prácticas del Fracaso hace parte de ellas.

\section{Las Prácticas del Fracaso como un lugar del indisciplinamiento, la contraacademia y la decolonialidad}

Desde el año 2013, en la Maestría de Estudios Artísticos de la Facultad de Artes ASAB, se desarrolla en el segundo semestre del año el espacio académico Prácticas del Fracaso, una asignatura electiva que funciona como un laboratorio interdisciplinario de investigación/creación y en el que han participado estudiantes, docentes y particulares, todos bajo la batuta de Maladrés (payaso que funciona como mi alter ego). En dicho espacio, a través de procesos de reflexión y creación colectiva y bajo una estructura conceptual que evoca los fundamentales del circo, entre los que se incluye la itinerancia, la proeza, la circularidad, el equilibrio, la muerte, etc. (Guy, 2001), se desarrollan dinámicas de creación, discusión y reflexión acerca del arte, la academia y el rol del artista-investigador en el contexto local, todo atravesado por el fracaso como detonante de creación.

La cátedra impartida por Maladrés está atravesada por diferentes aspectos que hacen parte de los cuestionamientos que la maestría se ha hecho durante sus años de funcionamiento y que son ahora también inquietudes del doctorado: la decolonización del pensamiento, el papel de la investigación/creación en el contexto científico/académico, la construcción de alternativas metodológicas para la comprensión del entorno, la pertinencia del artista como un agente que impacta en su contexto, las relaciones docente/estudiante, el arte como una forma de producción del conocimiento, entre otros. Estos elementos soportan una especie de «pertinencia paradójica», toda vez que las Prácticas del Fracaso han 
fungido como un Caballo de Troya dentro de la plataforma académica que ellas mismas cuestionan y desde las que también se han desprendido discusiones y debates que han alimentado los procesos del proyecto curricular. En Prácticas del Fracaso se piensan herramientas artísticas y pedagógicas diferentes que se contraponen a esa academia colonizada y deshumanizante.

A partir de lo anteriormente expuesto, la cátedra se ha consolidado como una práctica de carácter contraacadémico, en un diálogo plurivectorial crítico y creador que aspira a involucrar diferentes aristas interepistémicas e interestéticas, ya que no se desarrolla en un ámbito exclusivamente artístico, sino que también abarca otras discusiones académicas que han revertido en su desarrollo. Instituciones nacionales e internacionales han invitado a Maladrés a impartir talleres y conferencias en seminarios y congresos. Es así que, a través de este personaje, se ha podido tender un puente entre las prácticas artísticas y las prácticas académicas y pedagógicas, llegando incluso a irrumpir en espacios de divulgación científica, siendo citado en artículos y trabajos de grado, colándose con la finalidad de cuestionar crítica y tautológicamente aquello que le permite existir.
Por su parte Maladrés, como práctica performática, reviste otra serie de aspectos formales y conceptuales en los cuales vale la pena detenerse: la apertura de umbrales donde se conecta la realidad y la ficción, los límites entre la presentación y la representación, el análisis del discurso como una práctica artística que configura una propuesta plástica y dramatúrgica, la conformación de espacios de creación colectiva que disuelven la categoría de autor, el papel del espectador participante, la construcción del payaso blanco al borde de la hipérbole y lo grotesco, la abstracción como eje de construcción del mundo, el cuerpo como un lugar de límites y potencias, entre otros. Por todo eso, es indispensable reivindicar el cuerpo como una herramienta mediática a través de la cual se instauran los acontecimientos. Más allá del performance como un lenguaje o una disciplina plástica, es importante resaltar la corporeidad como herramienta de agenciamiento político, ético y cultural, dirigido hacia una comprensión no solo del cuerpo físico, sino del cuerpo social. En el momento en el que la modernidad negó la aiesthésis, negó lo somático y, por eso tal vez, es que el lugar central de resistencia contra todo el sistema es el cuerpo mismo. Se necesita pensar y repensar su liberación a

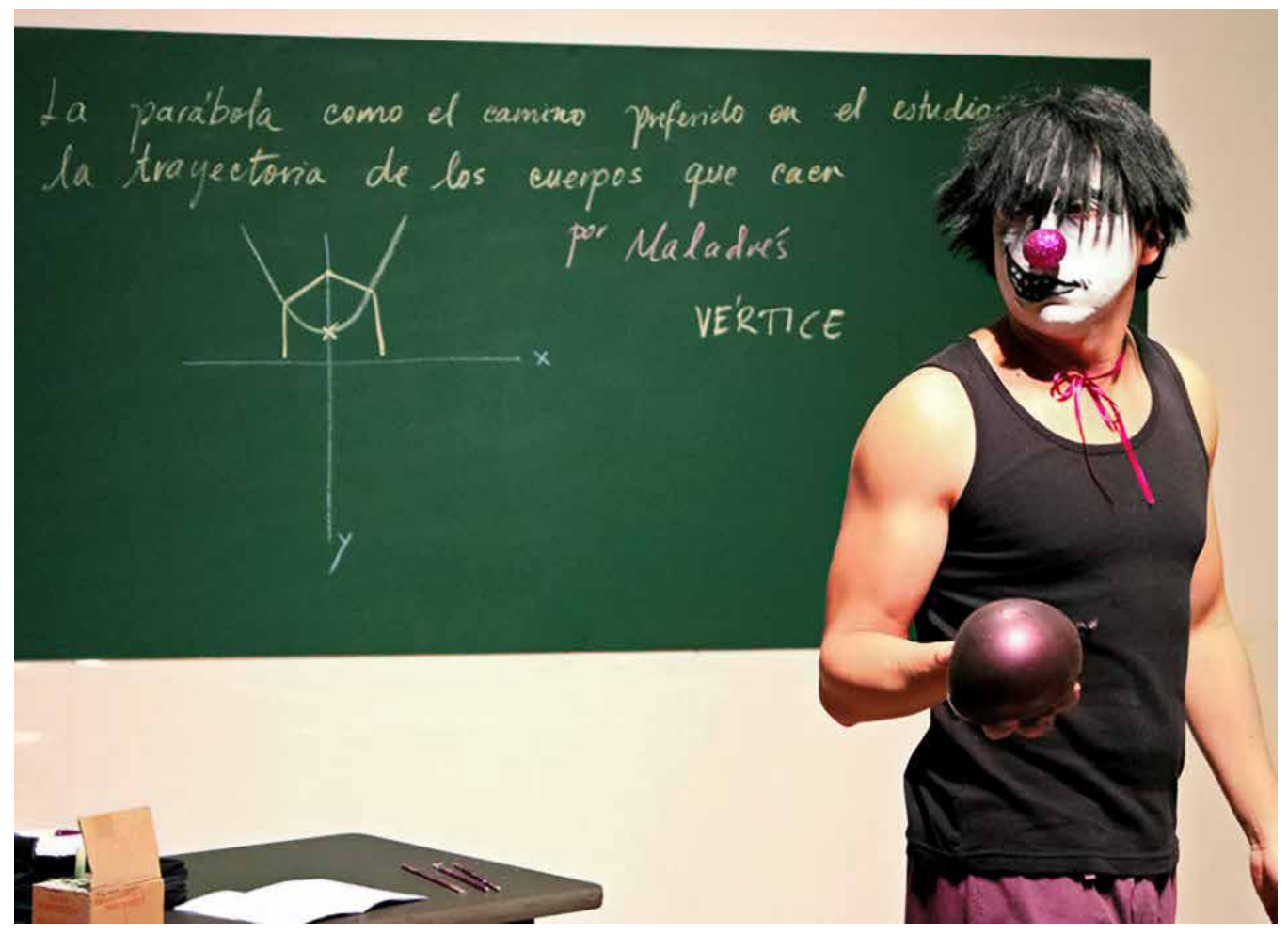

Imagen 9. Romero, G. La parábola como el camino preferido en la trayectoria de los cuerpos que suben y luego caen. UDFJC. 2013. 


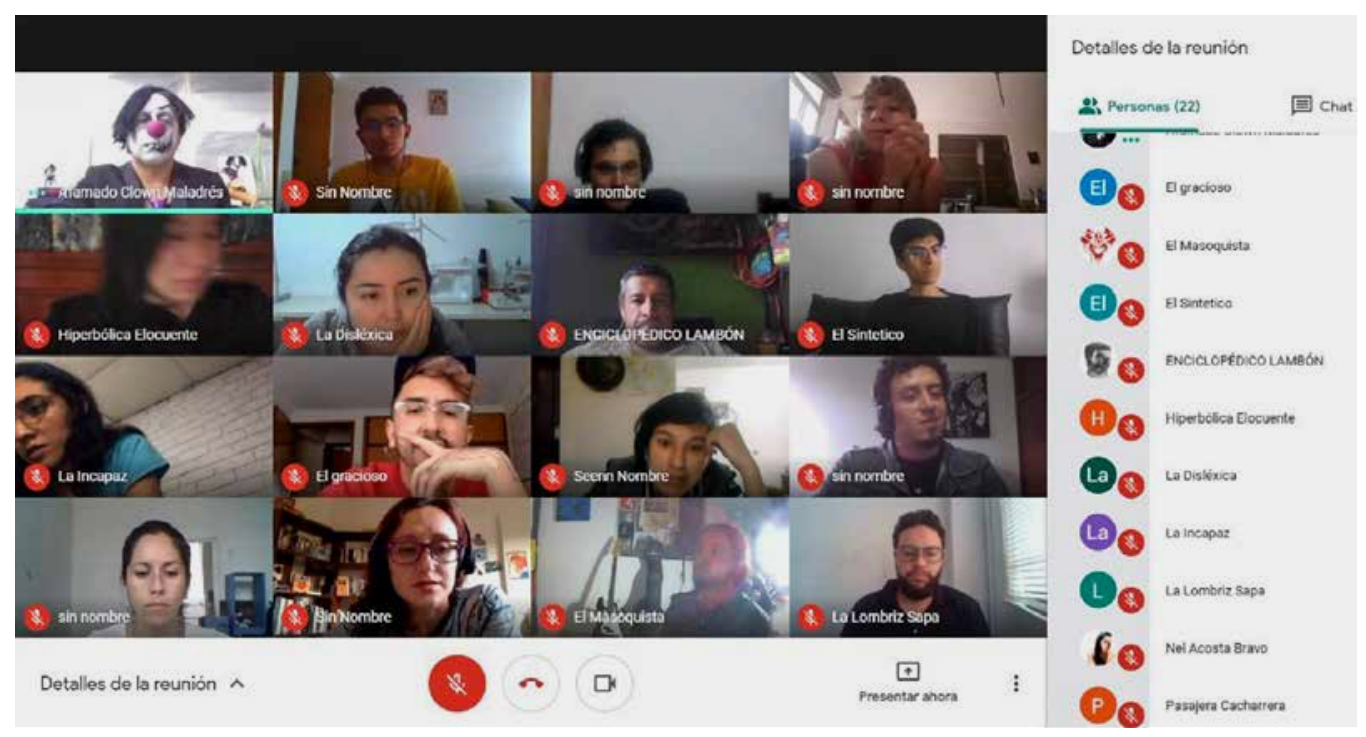

Imagen 10. Maladrés. Prácticas del Fracaso Virtual Pandemic Freak Show. UDFJC. 2020.

través de la posibilidad de explorar una multidimensionalidad de la corporeidad como herramienta del conocimiento (Rico, 2017) o de enfrentamiento ante lo ya instituido. Esta idea de entender el performance en múltiples dimensiones, conlleva la idea de pensar un cuerpo social o un cuerpo colectivo que, a través de las relaciones y las interrelaciones, tenga una incidencia en el devenir de la existencia. Se propone, entonces, la producción de conocimiento no solo desde la academia, sino también desde el calor de la experiencia y de la vida misma, ya que una «puesta en fracaso» requiere el compromiso total de la subjetividad.

En cuanto a la relacionalidad de los cuerpos, se apunta al colectivo humano, bajo restricciones históricas dadas por un pasado y una tradición, las cuales son reinterpretadas (Castoriadis, 1997) y que se convierten en vectores de fuga. Estos vectores ponen en tensión actos de resistencia, de renuncia, de emancipación y de democratización. Pensar en colectivo es, desde ya, una manera de oponerse a la verticalidad de nuestro sistema social y económico y, por ende, de las jerarquías que abundan en la oficialidad, ayudando a deconstruir también el mito egoestético del genio creativo solitario instaurado por la modernidad europea.

El escenario es, entonces, el aula de clases. El dispositivo «natural», la academia misma. Esta práctica artística solo es posible a través de la plataforma que ofrece la universidad y, por lo tanto, se fusiona realmente con el ejercicio pedagógico, convirtiendo a este último en obra y la obra de arte en una práctica pedagógica, rompiendo los límites, situándose en lo borroso, trascendiendo incluso la noción prosaica de la enseñanza en el salón de clases. Camnitzer, a propósito, afirma que el arte debería absorber a la educación, pues mientras el arte es una forma de pensar, la educación, tal y como está concebida hoy en día, es para entrenar (Camnitzer, 2015). Sin embargo, este autor se centra en el arte como un dispositivo para la educación, instrumentalizando el objeto artístico para que a través de su apreciación se llegue a un pensamiento crítico. Maladrés, por su parte, propone la inmersión en la práctica artística (la experiencia) y no el distanciamiento como una estrategia resolutiva.

\section{Campos de lucha}

Las Prácticas del Fracaso son ese tipo de paréntesis que, como las fronteras, se presenta como un campo de lucha donde prima el conflicto. ¿Cómo poder escapar de este barroco vital? ¿Cómo evitar el laberinto, el simulacro, la puesta en abismo, el rompimiento ficcional? ¿Podemos sobrevivir a tal paradoja?

En los estudios artísticos, el arte se sitúa en el pensamiento. Los artistas utilizan el lenguaje como materia prima de sus trabajos. Así, el arte deviene, poco a poco, un método que se confronta a otras metodologías más duras, como las científicas, pues hay otras verdades que la ciencia no alcanza a divisar y que la fantasía y la imaginación sí son capaces de develar. Es también, a través del lenguaje, que el arte trata de explicarse a sí mismo, mirándose su propio ombligo y permitiendo la construcción de estructuras metatextuales que 
desembocan en un nuevo barroquismo. Por otra parte, el arte ha dejado de representar la vida para volverse la vida misma. El performance rompe esta barrera y, con la presentación, vuelve a poner a la realidad como protagonista. Las acciones cotidianas, según Augusto Boal, tienen toda la potencia de volverse una acción artística, dependiendo del contexto y por una forma de osmosis.

La obra artística debe provocar una irrupción para suspender el devenir de la historia. Debe ser paréntesis, pausa, vacío. Así, se interrumpen las formas habituales de la sensibilidad. Ahora bien, hay que tomar distancia y alejarnos de lo central hegemónico para que las manifestaciones del arte toquen las fibras sociales, políticas y culturales. Por ello, desde Prácticas del Fracaso (y desde los estudios artísticos, claro está) se defiende lo marginal, la frontera, la diferencia, se defiende el lugar donde la práctica artística sea democrática, pues nos enfrentamos, por fin, ante la posibilidad de construcción de un sujeto político. Por ello, los estudios artísticos y las Prácticas del Fracaso son la oportunidad para revisar las ruinas de la academia, y pensar si hay que volver a ellas, reconstruirlas, reconfigurarlas o abandonarlas. Es también la oportunidad de preguntarnos qué hacemos, quiénes somos y cómo llegamos a ser lo que somos. Además, de pensarnos, desde el arte, las posibilidades de la interacción, la intercorporalidad, la colaboración, la conversación y la escucha, tan necesarios en nuestra existencia y en la época que nos tocó.

\section{Referencias}

Beckett, S. (1983). Worstward Ho. Barcelona: Lumen.

Cáceres, J. F. (2015). Práticas do Fracasso II. En

Castillo, S. (ed.), Corporeidades, sensibilidades e performatividades. Experiências e reflexoes (pp. 111115). Bogotá: UDFJC.

Calvino, I. (2012). Palomar. Madrid: Siruela.

Camnitzer, I. (2015). Arte y Pedagogía. Recuperado en https://tinyurl.com/3tyanhvp

Castoriadis, C. (1997). El imaginario social instituyente. En Zona Erógena, 35. Recuperado en www.educ.ar

Garzón Martínez, M. T. (2019). Contragenealogías del silencio. Una propuesta desde los estudios culturales feministas. En Calle 14 Revista de investigación en el campo del arte, 14(26). Recuperado en

https://doi.org/10.14483/21450706.15002

Gómez, P.P. (2016). Formación investigativa e investigación creadora de los estudios artísticos. Bogotá: sin publicar.

Gómez, P. P. (2018). Lugares de encuentro y colaboración entre los estudios culturales y los estudios artísticos. En Gómez P. (ed.), Aprender, crear, sanar: estudios artísticos en perspectiva decolonial (pp.

71-101). Bogotá: UDFJC.

Guy, J-M (dir.) (2001). Avant-garde Cirque! Les artes de la piste en révolution. Paris : Autrement, Collection Mutations No. 209.

Kaplún G. (2005). Indisciplinar la universidad. En Walsh, C (ed.), Pensamiento crítico y matriz (de)colonial (pp.213-250). Quito: UASB-Abya Yala.

Maladrés (2016). Discurso Inaugural. Bogotá: UDFJC. Recuperado en https://tinyurl.com/c74pexhx

Quijano, A. (2000). Colonialidad del poder y clasificación social. Journal of World-systems research, VI, 2,342-386.

Rico Bovio, A. (2017). Muerte y resurrección del cuerpo. Chihuahua: ACH-Plaza y Valdés.

Schlenker, A. (s.f). Indisciplinar el conocimiento: investigar desde/con las prácticas artísticas. Recuperado en https://tinyurl.com/22yh5bty 